\title{
Trends of Using Contraceptive Methods among Married Females of Reproductive Age Group in Village Mangokivirkan, District Gujranwala, Pakistan
}

Saadia Shahzad, Anjum Maqsood

Department of Community Medicine, Shalamar Medical and Dental College, Lahore, Pakistan.

\begin{abstract}
Background: Use of contraceptives in developing countries is very low, particularly in Pakistan it is $34 \%$.

Objective: To study trends of contraceptive use among married females of reproductive age group in a rural area of Pakistan and to identify possible risk factors influencing the use of contraceptives among the sample population.

Methods: It was a descriptive cross sectional study. A total of 213 married females of reproductive age were included in the study and multistage cluster sampling technique was applied. Study variables included socio demographic variables along with knowledge and practice of respondents regarding the use of contraceptives. Data collection instrument was a self-developed questionnaire and data was collected from 220 females.
\end{abstract}

Results: Mean age was $29.6 \pm 6.19$ and only $38 \%$ were using contraceptive method and $62 \%$ were not using any contraceptive method. Among the respondents $40 \%$ were counseled for Family Planning (FP) by some source. Highly significant association was found between contraceptive use and duration of marriage, decision making, family type, desired number of children, counseling for FP, in favor of FP, and number of children alive. Probable influencing predictors were found to be decision making of females, type of family, desired number of children, counseling for FP, and in favor of FP.

Conclusion: FP counseling needs to be enhanced on war footing at all levels with due cooperation of community participation.

Key Words: Females of reproductive age, married, contraceptive use, decision making.

\section{INTRODUCTION}

Contraceptives are the deliberate use of modern artificial methods or techniques to prevent pregnancy as a consequence of sexual indentures. At micro level some methods of contraception play a dual role of controlling family size and protection against the sexually transmitted diseases (STDs) ${ }^{1}$. Contraceptives are used by majority of married or in-union women in almost all regions of the world. In $201564 \%$ of married or in-union women of reproductive age group worldwide were using some form of contraception. On the other hand, use of contraception in the same year in least developed countries was like $12 \%$ in Mali, and $21 \%$ in Tanzania $^{2}$. Worldwide, oral contraceptive pills (OCPs) are used by 100 million of women in child bearing age; about 11.6 million women of United States use combined oral contraceptive pills (COCPs); about $80 \%$ of child bearing age American women have used OCPs at some point in time in their lives ${ }^{3}$. According to Pakistan
Demographic Health Survey (PDHS) 2012-2013, prevalence rate of use of contraceptives in Pakistan is $34 \%{ }^{4}$. Most of the women coming to health clinics in Pakistan have no idea about methods of contraception nor do they want to practice it because of social restrictions, poor health conditions, nutritional deficiencies and uterine prolapse at an early age due to repeated child births $^{5}$. Cultural restrictions in Pakistani society have a strong constraining effect on health improvement and it has hampered the implementation of effective and productive family planning (FP) strategies throughout the country ${ }^{6}$. Reproductive choices made by young women and men have an enormous health impact on schooling and overall transition to their adulthood ${ }^{7}$. History shows that largest cohort of young people enters into childbearing age, hence growth and population size will be determined by their behavior. Furthermore reproductive choices among young 
women are especially important as early child bearing and motherhood can impair their health ${ }^{8}$. Literature suggests that married adults wish to delay pregnancy in a young age or if they already have a child ${ }^{9}$. Evidence from literature suggests that contraceptive use and family planning programs are particularly responsible for improving mental health, three quarter reduction in maternal mortality ratio, decrease in infant mortality rate as well as decrease in morbidity. Globally about one-third of maternal deaths and one-tenth of child deaths can be reduced by an effective family planning program $^{10}$. Continuous use of contraceptives is not assured over a sustained period of time among women due to many reasons like side effects of methods of contraception, inconvenience of usage, lack of knowledge about the right way of using a particular method specifically among young women, limited access of young women to family planning services, issue of discontinuation of the contraceptive method among young women due to more unpredicted and irregular sexual activity ${ }^{11}$. Past studies have stated that success in avoiding pregnancies among adolescents often depend on having access to information regarding contraceptive methods and services. Despite best of family planning services, unplanned pregnancies do occur among adolescents and so the desired level of effective family planning remains low ${ }^{12}$. There are many barriers to the use of contraceptive methods among the adolescents on account of fear, embarrassment, and lack of knowledge; so this age group does need special education regarding use of family planning methods effectively ${ }^{13}$. Usage of contraceptives over a prolonged period of time is assured in many; and its discontinuation occurs due to various reasons like failure of the method, method features (e.g its side effects, and convenience of use $)^{14}$. Myths related to various contraceptive methods should be dispelled and facts should be made clear to women and young girls by health professionals in order to alleviate misconceptions and promote utilization of these methods ${ }^{15}$. Problem statement developed for current study isfor our local setup in Pakistan where social values, extended family system, family structure, and society make up is male dominating; women have less decision making power and female empowerment is not comparable to developed countries. Hence taking a decisive action regarding use of contraceptive method is an important aspect of family life which is governed and manipulated by many. Thus limiting the family size is not the first priority in majority of the cases. Conduction of this study is justified that it will give an overview of the trends of contraceptive use in rural area in Punjab. It will also give an insight into how various socio demographic variables are related to the adoption of contraceptive methods among married females of reproductive age group. Current study objectives are to study trends of contraceptive use among married females of reproductive age group in a rural area of Pakistan and to identify possible risk factors which may influence the use of contraceptives among the sample population. Research Question developed for present study was related to the probable risk factors which may influence the use of contraceptives in females of lower socio economic status residing in a central Punjab village in Pakistan.

\section{MATERIALS AND METHODS}

Cross sectional study design was applied, and study setting was one village in District Gujranwala in Punjab, Pakistan; with a total of one hundred households in it. Study universe was taken to be total population of the said district which was 64000 in 2016 and study was completed in a period of three months. Study population included married females of reproductive age group in the selected village. Sample size was calculated on Open Epi software using contraceptive prevalence ${ }^{4}$ of $16.65 \%$, and confidence interval of $95 \%$. Calculated sample size was 213. Multistage cluster sampling technique was adopted to recruit the sample subjects: in the first stage one village was selected randomly from a total of 800 villages in District Gujranwala in Punjab, Pakistan. In the second stage all households (100households in the selected village) were selected from the village and five (05) clusters of twenty (20) households each were marked. In the third stage females of 
reproductive age group were taken from the total sample households. Study variables selected for present study after extensive literature search were: a) socio demographic variables that included age of respondent, education level of respondent, educational status of husband, duration of marriage, family income per month, family type, decision making power with respondent, basic obstetrical history of the respondent; b) knowledge regarding family planning methods and FP practices that included use of contraceptive method, FP counseling, knowledge regarding FP, family size, consent to use FP methods, duration of use of a FP method, willingness to continue with adopted FP method, side effects of contraceptive method, type of contraceptive method in use, antenatal history in previous pregnancy, smoking history in respondent, other medication in use currently. Inclusion criteria were set as: 1) married females of reproductive age group 2) willingness of the respondent. Exclusion criteria were set as unmarried females of reproductive age group. Data collection tool was personal interview method and data collection instrument was a self-developed questionnaire. Data was collected in one month time. Village head was approached by the research team in order to get facilitation for data collection; after due communication upon the research idea and taking his consent for the conduction of this study in the village. Hence all house-holds were approached in that village one by one and a total of 220 females were recruited for this study after taking verbal informed consent; each female was interviewed upon the questionnaire in Urdu. Ethical considerations were duly observed for this study and information obtained was used for the purpose of current research only. Data analysis was planned as: calculation of descriptive statistics with mean and standard deviation, frequency trends for socio demographic variables noted, bivariate analysis and Risk analysis was done.

\section{RESULTS}

Data was collected from 220 female respondents; and non-response rate was zero. Data was entered on SPSS 17 and analyzed. Age range for female respondents was 20-45 year, mean $29.6 \pm 6.19$. Age range for respondent's husbands was 20-51 year, mean $32.1 \pm 6.70$. Among the respondents 14 reported to have family income $<10000 /$ month; whereas 77 reported to have $>10000 /$ month of family income.

Fig. 1: Education status of Respondent and Husband $(n=220)$

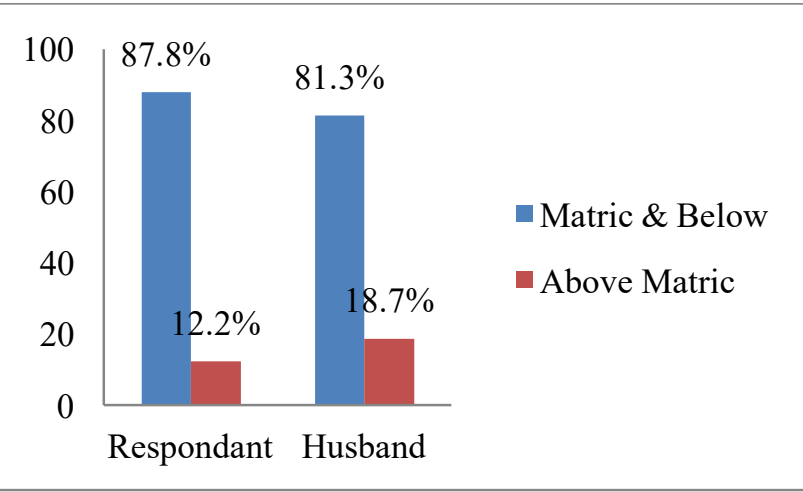

Fig. 2: Trends of Contraceptive Use among the study population $(\mathbf{n}=\mathbf{2 2 0})$

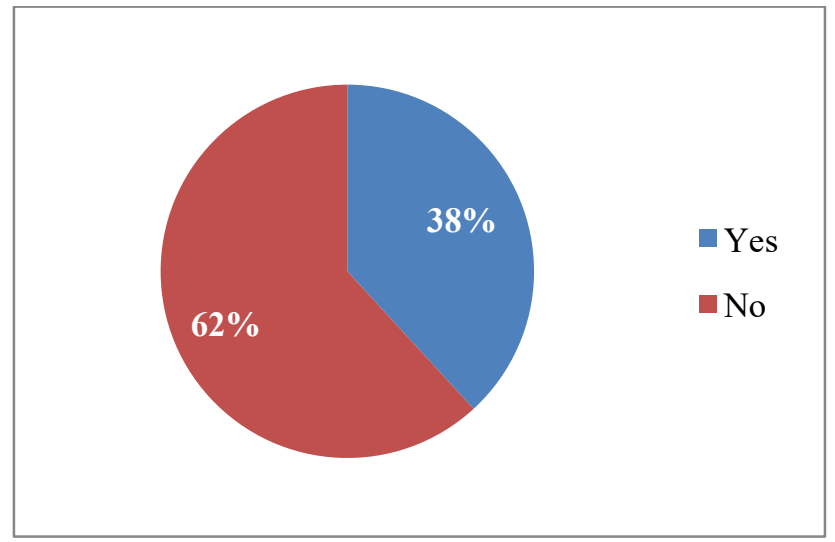

Fig. 3: Type of Contraceptives used

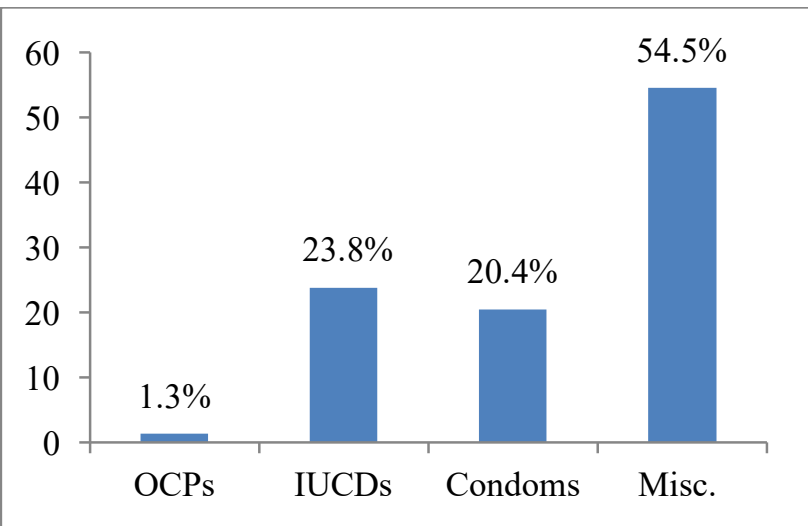


Present study found that $66 \%$ of the respondents were in favor of family planning methods and 34\% were not. Among the respondents 39\% had taken the decision to use contraceptives themselves, $2 \%$ did not, whereas $59 \%$ did not answer this query. In our respondents $38.9 \%$ were living in nuclear family type and $61.81 \%$ were living in extended family type. Data revealed that $78 \%$ of the respondents had support from extended family regarding their decision of adoption of family planning, and $22 \%$ did not have supportive extended family. During reproductive lives among the respondents $74 \%$ did not have any abortion. Results revealed that $76 \%$ of the respondents did not have any infant death during their reproductive lives. Present study found that $22 \%$ respondents had four alive children, 19\% had two, 18\% had one, $17 \%$ had three, $7 \%$ had five, and $2 \%$ each had six and seven alive children respectively; whereas $13 \%$ of the respondents did not answer for this question. Results showed that $78 \%$ of the respondents had regular antenatal checkup during last pregnancy whereas $22 \%$ did not go through with regular antenatal checkup. In this study $27 \%$ respondents were found to have $<5$ year of marriage duration and $73 \%$ had $>5$ year of marriage duration. Results showed that $47 \%$ respondents had desired number of children and $53 \%$ did not.

Fig. 4: Counseled for Family Planning

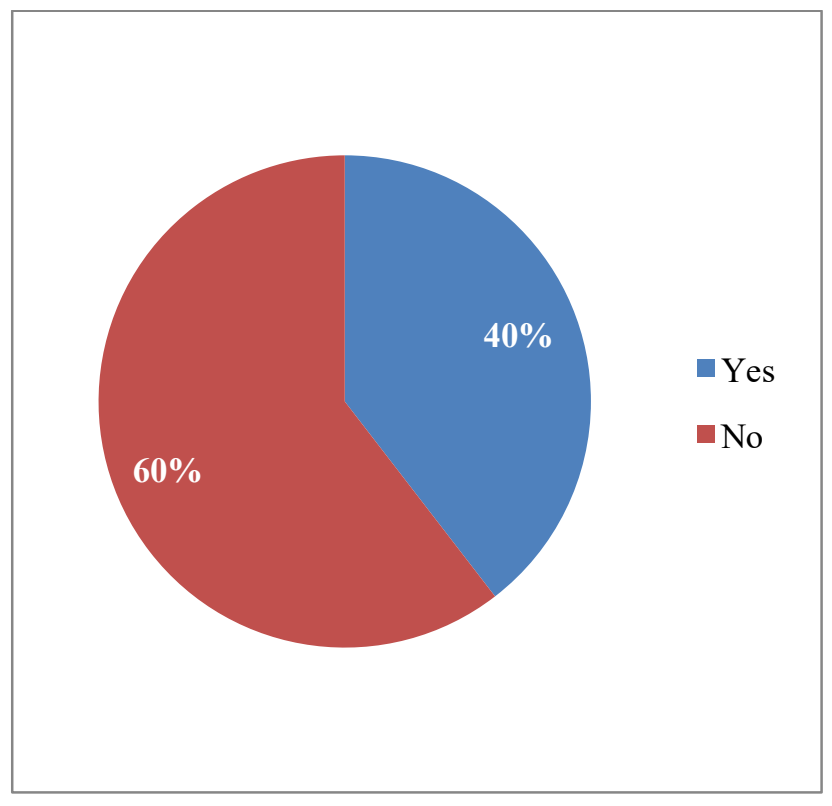

Fig.5: Study population Counseled by Whom

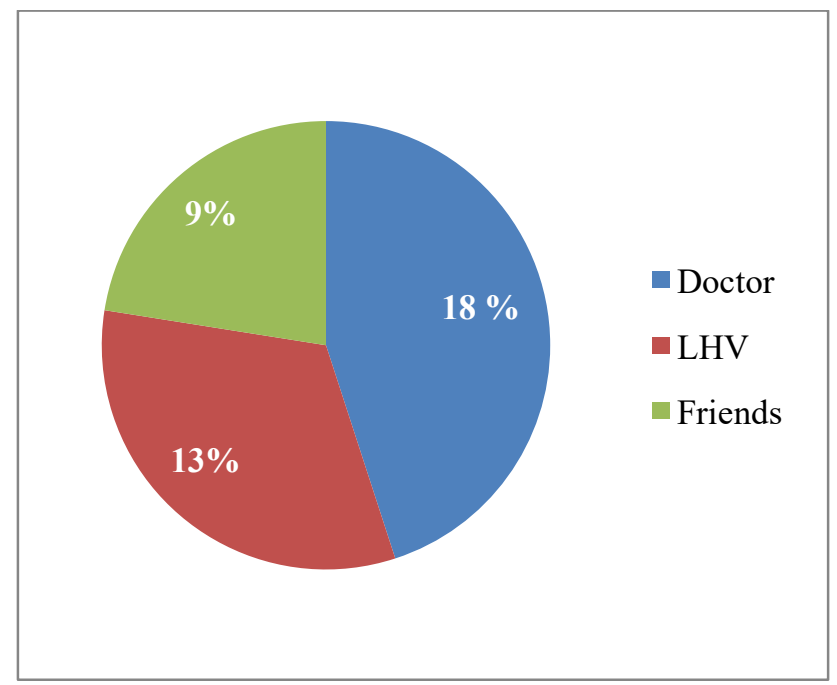

Results showed that $96 \%$ of the respondents did not have any problem with the use of FP method of their choice; and they had been using it for a varied time period each ranging from 3 months to 14 years. Bivariate analysis was applied to identify association between using a contraceptive method and socio demographic variables that included total family income, duration of marriage, decision making of the respondent, type of family, number of desired children, husband education, counseling for family planning, in favor of family planning methods, and number of children alive. Statistically significant association was found as given in the following table:

Table 1: Significant Association between Variables and Use of Contraceptives

\begin{tabular}{|c|c|c|c|}
\hline Variable & $\begin{array}{l}\text { Chi } \\
\text { square } \\
\text { value }\end{array}$ & df & p-value \\
\hline Duration of marriage & 21.013 & 1 & $.000^{* * *}$ \\
\hline $\begin{array}{l}\text { Took the decision yourself } \\
\text { for adoption of FP method }\end{array}$ & 15.377 & 1 & $.005 * *$ \\
\hline Type of family & 6.208 & 1 & $.015 * *$ \\
\hline $\begin{array}{l}\text { Do you have desired } \\
\text { number of children }\end{array}$ & 4.181 & 1 & $.045^{*}$ \\
\hline $\begin{array}{l}\text { Did anyone counsel for FP } \\
\text { method }\end{array}$ & 7.620 & 1 & $.006 * *$ \\
\hline In favor of FP & 20.770 & 1 & $.000 * * *$ \\
\hline Number of children alive & 21.013 & 6 & $.002 * *$ \\
\hline
\end{tabular}


Risk analysis was applied upon the variables and using a contraceptive method and Odds ratio was calculated as given:

Table 2: Probable Predictors as Identified by Risk Analysis with Contraceptive Method Use as Outcome

\begin{tabular}{|l|l|l|l|}
\hline Variable & $\begin{array}{l}\text { Un Adj. } \\
\text { OR }\end{array}$ & \multicolumn{2}{|c|}{$95 \%$ CI } \\
\hline & & Lower & Upper \\
\hline $\begin{array}{l}\text { Took the decision } \\
\text { yourself for adoption } \\
\text { of FP method }\end{array}$ & 29.250 & 2.715 & 315.179 \\
\hline Type of family & 2.049 & 1.161 & 3.615 \\
\hline $\begin{array}{l}\text { Do you have desired } \\
\text { number of children }\end{array}$ & 1.810 & 1.022 & 3.203 \\
\hline $\begin{array}{l}\text { Did anyone counsel } \\
\text { for FP method }\end{array}$ & 2.357 & 1.276 & 4.355 \\
\hline In favor of FP & 5.373 & 2.502 & 11.538 \\
\hline
\end{tabular}

\section{DISCUSSION}

Globally it has been duly acknowledged that massive population growth and size, uncontrolled migration from rural to urban areas can create pressure on the resources of a country; thus adversely affecting the economic prosperity of the country. This fact has greater impact upon the developing countries including Pakistan. At the moment Pakistan stands as fourth most populated country in the World; in spite of its limited resources. Pakistan is a country where fertility rate is very high and contraceptive prevalence rate is only $35.4 \%{ }^{4}$. Present study found that $88 \%$ of the respondents had education upto Matric level or below; and only $12 \%$ had education level above Matric. This finding is similar to another study conducted in a developing country that reported $74 \%$ of the women were illiterate; $8.7 \%$ had studied till primary level, $10 \%$ had completed secondary education, and only $6.5 \%$ had completed intermediate level ${ }^{2}$. Literacy level among women emphasizes the need for better education that will later on be the main stay for women empowerment. Findings of present study regarding family income and respondent's income are strongly supported by another study conducted by Kaziks; that also found $82 \%$ of families had income $<10,000 /$ month $^{8}$. Present study findings upon the use of FP method (38\% using contraceptives) and type of the contraceptive method in use is strongly supported by a survey report conducted in Pakistan that found low contraceptive prevalence of $20 \%$ in year $2005^{5}$.Present study found that $39 \%$ of the respondents had taken the decision themselves for the use of FP method. This finding is similar to another study conducted in the past that stated $50 \%$ of the women had chosen the FP method by their own decision; whereas in $41 \%$ of the women choice of FP method was made by their husbands ${ }^{6}$. Present study found that $39 \%$ of the respondents were living in nuclear family type, whereas $61 \%$ were living in extended family system. Majority $78 \%$ of the respondents had support from extended family regarding their decision of adoption of FP services. Present study also found that $78 \%$ of the respondents had regular antenatal checkup during previous pregnancy; whereas $22 \%$ did not go through with regular antenatal checkup. Present study findings regarding the counseling advantage of the respondents and the person who did the counseling is supported by other global researches that found that majority of young women had received very little education and information regarding contraceptives and family planning from parents, health services or elsewhere. Whatever little education they received, actually in most of the cases it simply reinforced the common misconceptions about modern contraceptives ${ }^{16}$. This study also found that $96 \%$ of the respondents did not have any side effects with the use of FP method of their choice; and each had been using the selected method for a varied period of time ranging from 3 months to 14 years. Bivariate analysis revealed statistically significant association between certain variables use of contraceptive method (Table 1). These findings are duly supported by other studies that also found significant association between contraceptive usage and factors as decision autonomy (P-value $<0.001$ ), number of children alive (P-value $<0.001)^{17}$. Few other studies that had employed similar variables for their investigation found women's education to be of paramount importance and significant role player ${ }^{18}$. Risk analysis was done in present study and it was found that decision making by the 
female, type of family, having the desired number of children, counseling for FP method, and willingness for FP method were identified as probable risk factors. So it can be safely stated that these factors are the probable predictors that influence the use of FP. This finding is consistent with another research finding that identified decision autonomy of the respondent as predictor for contraceptive use $(\mathrm{P} \text {-value }<0.001)^{17}$.

\section{Strengths of the study:}

Selection bias was controlled as all married females in reproductive age were taken as study subjects. Also total number of households in the selected village was taken in cluster sampling technique. Strength of the study was zero non response rates of the respondents.

\section{Limitations of the study:}

Major constraint during conduction of the study was availability of time for data collection and small sample size. Non representativeness of the sample was also a limitation.

\section{REFERENCES}

1. Hubacher D, Mavranezouli I, McGinn E. unintended pregnancy in Sub Africa: Magnitude of the problem and potential role of contraceptives implants to activate it. Contra 2008; 78: 73-8

2. Bearinger L.H, Sieving R.E, ferguson J, Sharma V. Global perspectives on the sexual and reproductive health of adolescents: patterns, prevention, and potential. Lancet; 2007; 369: 1220-1231

3. Agha S. intentions to use contraceptives in Pakistan: implications for behavior change campaigns. BMC Public Health 2010; 10: 450

4. Pakistan Demographic and Health Survey 2013, Pakistan Contraceptive 2014-15

5. Sather Z.A, Mason Ko. How female education affects reproductive behaviors in Urban Pakistan. Asian and Pacific Population Form 1993; 6(4): 013103

6. Hakim A, Sultan M, UD DIN Ahmed F. Pakistan Reproductive Health and Family Planning Survey (2000-01). Preliminary report Islamabad. National Institute of Population Studies; 2001.

7. Lloyd C. Growing up Global: The changing transitions to adulthood in developing countries. Washington DC: National Academic Press, 2005
8. Blanc A.K, Tsui A.O, Croft T.N. Patterns and trends in adolescents contraceptive use and discontinuation in developing countries and comparison with adult women. International Perspectives on Sexual and Reproductive Health 2009; 35(2): 63-71

9. Cleland J, Ali M, Shah I. Trends in reproductive behavior among single verses married young women in Sub-Saharan Africa: The big picture. The European Journal of Contraceptive and Reproductive Health Care 2006; 14(28): 17-22

10. Samule H.N. Prevalence and correlates of contraceptive use among female adolescents in Ghana. BMC Womens'Health 2015; 15: 60

11. Ali M, Cleland J. Reproductive consequences of contraceptive failure in 19 developing countries. Obstetrics and Gynecology 2004; 104(2): 314-320.

12. Games K. Contraceptive method use by adolescents in a Brazilian state capital. Journal of Pediatrics and Adolescents Gynecology 2008; 1(4): 213-219.

13. Biddlecom A. sAdolescent's views of and preferences for sexual and reproductive health services in Burkina Faso, Ghana and Uganda. Africa journal of Reproductive Health 2007; 11(3): 99-110.

14. Blanc A, Way A. Sexual behavior and contraceptive knowledge and use among adolescents in developing countries. Studies in Family Planning 1998; 29(2): 106-116

15. Hubert A, Samuel H.N. Trends in contraceptive practice among women in reproductive age at a health facility in Ghana. Contraception and Reproductive Medicine 2016.

16. Castle S. Factors influencing young Malian's reluctance to use hormonal contraceptives. Stud FamPlann 2003; 34: 186-199

17. Saleem S, Bobak M. Women's autonomy, education and contraception use in Pakistan: a national study. Bio Med Central 2005. Available at: http://www.reproductive-healthjournal.com/content $/ 2 / 1 / 8$

18. Fikree F.F, Khan A, Kadir M.M, Sojan F, Rahbar M.H. What influences contraceptive use among young women in urban squatter settlements of Karachi Pakistan? International Family Planning Perspectives 2001; 27: 130-136

\section{Corresponding Author:}

Dr. Sadia Shahzad

Shalamar Medical \& Dental College, Lahore

Email: saadia.shahzad@sihs.org.pk 